\title{
Effects of the COVID-19 Pandemic on Physical Activity Behavior across Domains and Settings
}

\author{
Gina M. Besenyi ${ }^{1}$, Oziel Pruneda ${ }^{1}$, Emily L. Mailey ${ }^{1}$, Justin A. DeBlauw ${ }^{1}$, Cassandra M. Beattie ${ }^{1}$, \\ Jeanette Gustat ${ }^{2}$, and Katie M. Heinrich ${ }^{1}$
}

\author{
${ }^{1}$ Department of Kinesiology, College of Health and Human Sciences, Kansas State University, U.S.A. \\ ${ }^{2}$ Department of Epidemiology, School of Public Health and Tropical Medicine, Tulane University, U.S.A.
}

\begin{abstract}
COVID-19 restrictions and alterations to daily living (e.g. working from home, caregiving responsibilities) necessitated changes in physical activity (PA) behavior. The purpose of this study was to understand how PA within specific domains and behavior settings changed during the COVID-19 pandemic, as well as the extent to which PA increased or decreased as a function of participants' gender, work location (i.e., home vs. jobsite) and caregiving responsibilities. An e-survey, conducted April-June 2020, examined changes in PA across domains and settings in a national sample of 805 adults. Respondents reported domainspecific increases in household and recreational PA, but decreases in active transportation, occupational PA, and public transportation use. Weekly minutes of PA changed significantly across all behavior settings, with reported increases in homebased, neighborhood, parks/trails, and total PA, and decreases in PA through recreational sports and fitness facilities. Total weekly PA minutes increased by $10.6 \%$. Those with caregiving responsibilities reported increases in household PA and PA frequency, whereas those without caregiving responsibilities were more likely to report increases in sitting. Those working from home reported a larger increase in neighborhood PA. Those working at a jobsite with caregiving responsibilities reported less weekly PA, while those working from home with caregiving responsibilities reported greater weekly PA. The overall increase in weekly PA minutes and ability to adapt to different domains/settings was encouraging. Future interventions should capitalize on domain- and setting-specific changes, while considering work location and caregiving responsibilities to develop innovative PA promotion strategies.
\end{abstract}

Keywords: COVID-19, Physical activity, domains, behavior settings, work, caregiving 
The coronavirus disease 2019 (COVID-19) is a novel form of the coronavirus first identified in 2019 in Wuhan, China (World Health Organization, 2020). COVID-19 is a respiratory illness that can spread from person to person via infected respiratory droplets, with health effects ranging from asymptomatic to severe including death (CDC, 2019). Due to exponential increases in cases, the World Health Organization (WHO) declared the COVID-19 outbreak a global pandemic in March 2020 (Cucinotta \& Vanelli, 2020). To prevent the spread of the disease, public health agencies such as WHO and the Centers for Disease Control and Prevention (CDC) developed multiple recommendations including frequent hand washing, employing physical 'social' distancing of at least $6 \mathrm{ft}$, mask wearing, business closures, stay-at home orders, quarantines post exposure, and maintaining a healthy lifestyle including quitting smoking, eating a proper diet, and staying physically active (Center for Disease Control and Prevention, 2020; World Health Organization, 2020).

Physical activity (PA), in particular, is an important healthy lifestyle behavior that has a variety of physical, mental, and social benefits. A wide body of literature indicates that PA helps prevent and/or treat many physical and mental health conditions (Powell et al., 2019). PA can reduce the risk and severity of COVID-19 infection through several biological processes. For example, PA can improve the functioning of the immune system, reduce inflammation, and improve the body's response to vaccines (Campbell \& Turner, 2018; Jones \& Davison, 2019; Lee et al., 2019; Nieman \& Wentz, 2019; Woods et al., 2020). Decreases in PA are thought to cause a 'downregulation' of the immune system resulting in harmful 'second wave' effects, particularly for those with COVID-19 (Woods et al., 2020). Additionally, PA is effective for mitigating a variety of chronic conditions (e.g., heart disease, diabetes, cancers) that may increase the risk of severe complications among those with COVID-19. PA can also play an important role in managing mental health symptoms such as stress and anxiety resulting from COVID-19 (e.g., increased health concerns, job loss, reduced income, social isolation) (Callow et al., 2020; López-Bueno et al., 2020; Maugeri et al., 2020; Schuch et al., 2020). Research shows that PA has a positive impact on mental health disorders and symptoms such as anxiety, stress, depression, and emotional well-being (Ammar et al., 2020; Basso \& Suzuki, 2017; Galper et al., 2006) and has been recommended as a therapeutic treatment for physical and mental health during the pandemic (Amatriain-Fernández et al., 2020).

Despite many benefits, alterations in daily living during COVID-19 necessitated changes in PA behavior (Knell et al., 2020). Physical distance recommendations, mask wearing, stay-at-home orders, quarantine, and closure of non-essential businesses and public services all contributed to changes in PA habits. A recent study completed by Barkley et al. (2020) examined COVID-19 pandemicrelated acute effects on PA and sedentary behaviors. A pool of 398 university students, faculty, and related personnel self-reported PA levels, sedentary behavior, and body weight pre- and post-cancellation of in-person classes via the Godin PA questionnaire and International Physical Activity Questionnaire (IPAQ). The pandemic restrictions altered the way in which university students engaged in PA with a significant reduction in mild PA of $33.7 \%$ post cancellation of in-person classes, along with a $13.9 \%$ increase in weekly sitting time (Barkley et al., 2020). Several studies have reported an increase in sedentary behavior as well as decreases in PA during mandated restrictions. Individuals who reported being usually active before pandemic restrictions reported less moderate-tovigorous physical activity (MVPA) and a reduction in overall PA during restrictions (Barkley et al., 2020; Karuc et al., 2020; Schuch et al., 2020). Inactive and physically active persons became less active by $40.5 \%$ and $22.4 \%$, respectively. (Lesser \& Nienhuis, 2020). Likewise, a study of U.S. adults found reductions in walking ( -2232 steps/day) and moderate (-92.4min/week) and vigorous ($66.9 \mathrm{~min} /$ week) PA, particularly in early phases of the COVID-19 pandemic (Dunton et al., 2020).

Changes in PA participation may be due to a variety of influences. Important influences to consider are behavior settings for PA (e.g., homes, neighborhoods, fitness facilities) representing different domains of active living (i.e., active recreation, active transportation, household activities, occupational activities) (Sallis et al., 2006). For example, the COVID-19-forced closure of PA facilities such as gyms and yoga studios limited indoor PA opportunities. Yet, facility closures prompted increased opportunities for alternative settings and forms of recreational PA. Many recommendations to maintain PA during early stages of COVID-19 shutdowns highlighted home-based, outdoor, and online activities (Chen et al., 2020; Jurak et al., 2020). Most Canadian adults opted for PA in home or neighborhood settings, and those who were previously active had significantly more outdoor PA during COVID-19 (Lesser \& Nienhuis, 2020). Altered daily routines also eliminated settings for occupational and transportation related PA. For example, the percent of the U.S. population working entirely from home increased from 8.2\% in February 2020 to 35.2\% in May 2020 (Bick et al., 2020), along with surges in telecommuting and online shopping, as well as increases in risk perception of using public transportation options (bus, carpool, airplanes) (Shamshiripour et al., 2020). Another report indicated that 2 out of 3 working parents had to change their childcare arrangements due to COVID-19, and that $75 \%$ had children at home during work hours (U.S. Chamber of Commerce Foundation Center for Education and Workforce, 2020).

Because of the numerous forced lifestyle changes during COVID-19, little is known about how people are participating in PA during the pandemic, particularly with respect to PA settings and domains. Therefore, the purpose of this study is to understand how PA within specific domains and behavior settings has changed during the COVID-19 pandemic. Additionally, to better understand the impact of COVID-19 restrictions on PA behavior within domains and settings, we explored the extent to which PA increased or decreased as a function of participants' gender, work location (i.e., home vs jobsite) and caregiving responsibilities. 


\section{Methods}

\section{Study Design and Participants}

This cross-sectional study assessed PA behavior before and during the COVID-19 pandemic via an online survey. The survey took approximately 15-20 minutes to complete and was open to adults of all racial, ethnic, and income groups or geographic locations in the U.S. Participants had to be at least 18 years of age and able to read English. A convenience sampling strategy was employed and recruitment materials encouraged participants to aid snowball sampling by forwarding the survey link on to others. Recruitment occurred via social media posts, emails, organizational and news outlets, and listservs. At the beginning of the survey, participants read a short description of the study purpose and completed informed consent by clicking 'agree' to continue. Institutional Review Boards at [blinded] University (\#10135) and [blinded] University (\#202-784) approved all study procedures.

\section{Data Collection}

Data was collected from April to June 2020 via an online survey administered through Qualtrics Online Survey Software (Provo, UT). During this time period, 42 U.S. states and territories had issued mandatory stay-athome orders resulting in significant decreases in population movement (Moreland et al., 2020). Participants could either complete the survey on a computer or mobile device. The survey queried changes in PA behavior from before to during COVID-19 including the frequency, duration, domain, setting, and weekly minutes of PA. Survey questions were sequenced so primary questions (changes to PA minutes per week within settings) appeared first.

\section{Measures}

\section{Physical Activity}

PA questions were developed to capture self-reported change in PA behavior within specific settings due to the COVID-19 pandemic. Perceived changes in PA domains, duration, frequency, and sedentary time were collected via a 5-point Likert scale ranging from much lower (1) to much higher (5) with a three indicating 'about the same'. PA domains captured were based on active living domains that included recreational PA, occupational PA, active transportation, public transportation, and household PA (Sallis et al., 2006). Data was recoded as lower (1), same (2), and higher (3). Changes in PA mode, location, and reason were captured by a 5-point Likert scale from strongly disagree (1) to strongly agree (5). If participants agreed that their PA behavior had changed during the pandemic, they were asked to complete an open-ended question describing how their PA had changed. PA participation before and during COVID-19 was assessed in five different settings (i.e., parks/trails, recreational sports, in neighborhoods, at home, or in fitness facilities). Participants also reported weekly minutes of PA before and during COVID-19. Participants first reported weekly minutes of PA before COVID-19 retrospectively for each setting, and then reported weekly minutes of PA during COVID-19 (i.e., currently) for each setting. Outliers over 1800 minutes (30 hours) per week were removed. Total weekly PA minutes before and during COVID-19 were calculated by summing PA weekly minutes across all five settings and were recoded into no PA ( 0 minutes), low insufficient (1-59 minutes), moderate insufficient (60-149 minutes), sufficient (150-299 minutes), and exceeding (>300 minutes) by setting.

\section{Daily Living}

As noted above, changes in daily living due to the pandemic and related restrictions may influence PA behaviors and the domains and settings in which they occur. Therefore, respondents were asked information about their daily life during the COVID-19 pandemic including work location (home or jobsite), and whether they had school-aged children or infant/toddlers at home or other caregiving responsibilities (e.g., elderly or sick family members). For analyses, two dichotomous variables were created for work location (working exclusively from home vs. doing any work at jobsite) and caregiving ("yes" to any caregiving responsibilities vs. "no" to all).

\section{Demographic Information}

Demographics were assessed using standard questions from national surveillance systems (e.g., Behavioral Risk Factor Surveillance Systems, BRFSS; National Health and Nutrition Examination Survey, NHANES). Demographics captured included gender (male (M)/female $(\mathrm{F})$ ), age, race (categorized as white/non-white), ethnicity (Spanish, Hispanic, or Latino), education, income, marital status, employment status (categorized as working/not working), number of people and children under 18 in the household, housing type (categorized as single- or multi-family housing or other), and country and state of residence.

\section{Analysis}

Data was analyzed in SPSS 27 (SPSS, Chicago, IL). Descriptive statistics were assessed using mean and standard deviation (SD) for continuous variables and count (n) and absolute frequencies (\%) for categorical variables. Chi-square analyses were conducted to explore whether the percentages of participants with increased or decreased PA in various domains differed by gender, work location or caregiving status. Given the non-parametric nature of weekly minutes of PA within settings, paired sample t-tests and Wilcoxon signed-rank tests examined changes in PA from before to during COVID-19. Repeated measures ANOVAs and ANCOVAs explored differences in PA categories across settings before and during COVID-19 and between-subject interactions with work location (home vs jobsite), caregiving (yes [Y]/no $[\mathrm{N}]$ ), and gender (M/F). Open-ended questions were assessed using a constructivist grounded theory approach allowing participant comments to add experiential meaning and context to indicated changes to PA behavior (Charmaz, 2006). 


\section{Results}

A total of 1224 survey respondents completed informed consent. Of these, 955 completed PA questions. For the current analysis, we removed respondents with incomplete demographic information $(n=136)$ and those living outside of the U.S. $(n=14)$, resulting in a final sample of 805 participants. Of these, the majority were white $(84.7 \%)$ and female $(78.0 \%)$, with a mean age of 38.7 years $(\mathrm{SD}=14.9)$. For further insights, see Table 1. Most respondents had a graduate degree $(53.0 \%)$ and were employed $(78.2 \%)$, and $35.2 \%$ had an income of $\$ 100,000$ or more. The majority $(64.5 \%)$ reported being in a relationship (either married or as an unmarried couple) and living in single-family housing $(67.3 \%)$, with an average of $2.8(\mathrm{SD}=1.4)$ people in the household, with $0.6(\mathrm{SD}=1.0)$ persons under the age of 18 . Respondents represented 42 out of 50 states across the U.S., with the majority from the Midwest (67.0\%) or South $(21.2 \%)$. Daily life questions indicated that that majority were working exclusively from home $(66.3 \%)$ rather than at a traditional job site (16.1\%). Just under one third of participants $(31.6 \%)$ indicated they had caregiving responsibilities such as school aged children at home (20.9\%), infants or toddlers at home $(10.1 \%)$ or other caregiving responsibilities $(8.1 \%)$.

Figure 1a displays self-reported changes in PA during the COVID-19 pandemic across the five domains. The greatest number of respondents indicated higher amounts of recreational (44.9\%) and household PA (55.9\%) during COVID-19, but reported decreases in occupational PA $(55.1 \%)$, active transportation $(57.1 \%)$, and public transportation use (25.7\%). Respondents also reported changes in PA and sedentary behavior. As shown in Figure $1 \mathrm{~b}$, many respondents reported higher time sitting (60.7\%), but many also indicated increases in PA duration (46.2\%) and frequency $(43.9 \%)$. Around one-fourth of the sample $(19.1 \%-35.8 \%)$ indicated no change in PA domain or participation. The majority of respondents also agreed or strongly agreed that changes occurred in their mode (76.8\%), location $(79.0 \%)$, and reasons for PA $(53.5 \%)$ (Figure 1c).

As seen in Table 2, participants working at a jobsite were less likely to report reductions in occupational PA $\left(\chi^{2}=41.83, p<0.001\right)$, active transportation $\left(\chi^{2}=26.08, p<\right.$ $0.001)$, and public transportation use $\left(\chi^{2}=10.71, p=0.005\right)$ than those working exclusively from home, but participants working from home were more likely to report increases in recreational PA $\left(\chi^{2}=9.80, p=0.007\right)$. Participants with caregiving responsibilities were more likely to report increases in household PA $\left(\chi^{2}=9.82, p=0.007\right)$ and frequency of PA $\left(\chi^{2}=8.21, p=0.02\right)$ than participants without caregiving responsibilities, whereas participants without caregiving responsibilities were more likely to report increases in sitting than those with caregiving responsibilities $\left(\chi^{2}=20.55, p<0.001\right)$. Caregivers were also more likely to report that their reasons for PA had changed $\left(\chi^{2}=13.44, p=0.001\right)$. Finally, females were more likely than males to report that their recreational PA $\left(\chi^{2}=16.61, p\right.$ $<0.001)$, PA frequency $\left(\chi^{2}=10.52, p=0.005\right)$, PA duration $\left(\chi^{2}=20.38, p<0.001\right)$ and PA mode $\left(\chi^{2}=5.97, p=0.05\right)$ had increased or changed, whereas males were more likely to report that they had stayed the same.

Based on the Wilcoxon signed-rank tests, weekly minutes of PA behavior across all settings significantly changed from before to during COVID-19 ( $\mathrm{p}<0.05$ for all settings) (Figure 2). Increased weekly minutes of PA were reported for parks/trails, neighborhoods, and home-based settings, while fewer minutes of PA were reported for recreational sports and fitness facilities. Weekly minutes of home-based PA had the largest increase at $101.0 \%(Z=$ $18.9, \mathrm{p}<0.001)$, while fitness facilities showed the largest decrease during COVID-19 restrictions compared to before at $98.1 \%(Z=-19.0, \mathrm{p}<0.000)$. Overall, weekly minutes of total PA significantly increased by $10.6 \%$ from 391.9 $\mathrm{min} /$ week before to $433.5 \mathrm{~min} /$ week during COVID-19 ( $Z=$ $4.428, \mathrm{p}<.000)$.

To reduce sample skewness and kurtosis, weekly minutes of PA within settings were categorized as shown in Table 3. Despite this, sample skewness and kurtosis was still too great to examine main or interaction effects for fitness facility PA. Results of the repeated measures ANCOVAs comparing differences in PA across remaining settings before and during COVID-19 by work location (home vs jobsite), caregiving (Y/N), and gender (M/F) are shown in Table 4. Significant main effects were found for recreational sports $(F(1,641)=66.00, p<0.001)$, neighborhood PA $(F(1,638)=26.44, p<0.001)$, and homebased PA $(F(1,641)=120.31 p<0.001)$. Recreational sport PA decreased, while neighborhood and home-based PA increased from before to during COVID-19. Multiple significant between-subject interactions were noted. Males experienced a greater decline in recreational sport PA than females from before to during COVID-19 $(F(1,641)=$ $10.80, p=0.001)$. Those working from home saw a larger increase in neighborhood PA from before to during the pandemic $(F(1,638)=4.93, p=0.027)$. Those without caregiving responsibilities reported a greater increase in home-based PA than those with caregiving responsibilities $(F(1,641)=6.31, p=0.012)$, though those with caregiving responsibilities reported more home-based PA at both time points. Those working at a jobsite experienced a decline in total PA, while those working from home reported an increase in total PA $(F(1,641)=9.85, p=0.002)$. In particular, those working at a jobsite that also had caregiving responsibilities reported less weekly PA, while those working from home with caregiving responsibilities reported greater weekly PA $(F(1,646)=4.23, p=0.04)$.

Responses to the open-ended survey questions provided additional context to describe the changes reported in the quantitative results. Table 5 displays seven themes identified in the quantitative data related to changes in physical activity, with exemplar quotes for each. Themes included (a) decreases in occupational activity, (b) decreases in active transportation, (c) increased sitting time, (d) no PA at fitness facilities, (e) increases in outdoor PA, (f) increases in home-based activity, and ( $g$ ) new modes of PA. Many participants described reductions in occupational and transport-related activity as a function of working from 
home (i.e. their reason for PA changed due to changes in settings). Even if they did not have physically active occupations, most incidental activity they had accumulated by walking to meetings, talking to colleagues, taking the stairs, etc. was eliminated with the shift to remote work. These changes also contributed to an increase in sitting time, as participants were spending long hours in front of a computer in virtual meetings.

Many participants also described how the closures of fitness facilities had influenced their PA behaviors. Without the option of going to a fitness facility, individuals were forced to develop creative solutions to stay active at home or outdoors. Often these changes in settings necessitated a change in PA mode (e.g., doing outdoor or home-based PA such as walking or yoga rather than using gym-based weight and cardio machines), as participants did not have access to the same resources and exercise equipment in the home environment. However, many participants shared positive experiences associated with these changes; they engaged in new types of PA that they would not have otherwise tried, tackled indoor and outdoor home projects, took frequent walks in the neighborhood, and explored outdoor parks and trails they had not had time to visit before the pandemic. As a result, the majority of individuals were able to maintain or increase their PA frequency $(73.6 \%)$ and duration $(66.1 \%)$ in spite of the COVID-19 pandemic.

\section{Discussion}

The purpose of this study was to assess changes in PA within five domains and five behavior settings during the COVID-19 pandemic as well as explore how PA changed as a function of gender, work location, and caregiving responsibilities. Respondents self-reported domain-specific increases in household and recreational PA, but decreases in active transportation, occupational PA, and public transportation use. These findings are reflective of increases in working from home and risk perception of using public transportation previously noted (Bick et al., 2020; Shamshiripour et al., 2020). Respondents reported their weekly minutes of PA changed significantly across all behavior settings, such that there were increases in homebased, neighborhood, parks/trails, and total PA, and decreases in PA through recreational sports and fitness facilities. Males in particular reported decreased recreational sport PA during the pandemic, whereas females were more likely to report increased recreational PA overall.

Our results suggest that while the pandemic created a shift in usage of specific PA domains/settings (e.g., reduced workplace access, use of active and public transportation, and access to fitness facilities), respondents were able to offset these restrictions by increasing recreational and household PA at home and outdoors, for a $10.6 \%$ increase in total PA. In particular, those working from home significantly increased their neighborhood and total PA, while those with and without caregiving responsibilities saw increases in home-based PA, although more so for caregivers. Interestingly, those working at a jobsite that also had caregiving responsibilities saw a decline in total PA during the pandemic. On the other hand, those working from home that also had caregiving responsibilities saw an increase in total PA. A recent study by Del Boca et al. (2020) found that with the exception of those continuing to work at a jobsite, all of the women in the study spent more time on housework than before COVID-19. Although we found few gender specific interactions, other studies note the increased burden of childcare on parents during the pandemic, particularly mothers (Carlson et al., 2020; Prados \& Zamarro, 2020). While some participants remarked on the loss of incidental workplace activities (e.g., walking to meetings), active transportation (e.g., no walking to school), and fitness facility access, other comments highlighted how respondents had increased their PA at home (e.g., home workouts, playing with children), and outdoors (e.g., hiking, gardening), and discovered new ways to stay active that were affordable and sustainable (e.g., yoga, high intensity interval training [HIIT]).

The overall increase in PA for our sample is in contrast with previous research that reported significant decreases in MVPA and overall PA, which was true for both previously inactive and physically active adults (Barkley et al., 2020; Karuc et al., 2020; Schuch et al., 2020; Lesser \& Nienhuis, 2020). Another previous study found reduced walking, moderate, and vigorous physical activity among U.S. adults (Dunton et al., 2020). However, the same study found that those who reported at least $30 \mathrm{~min}$ of PA per week, also reported the most common settings for their activity during COVID-19 as home-based (75.0\%), neighborhood (69.9\%), and parks/trails $(27.1 \%)$, which agrees with previous research among Canadians as well as our findings for the same behavior settings (Dunton et al., 2020; Lesser \& Nienhuis, 2020). It is possible that the focus of our study on ascertaining PA within specific domains and settings may have allowed for our survey respondents to better recall their activity based on the contextual cues provided within our questions rather than having to recall days and minutes of PA each day of their week for walking, moderate, and vigorous activities. In essence, that focus allowed us to examine, and participants to consider, the nuances in where their PA was taking place and consider various types of PA that they were doing in different domains and settings (beyond only recreational PA), which showed an overall increase.

Our respondents reported significantly more time spent sitting, especially for those with no caregiving roles. This agrees with results from a survey by Qi et al. (2020) of Chinese adults who reported significant increases in sedentary time during COVID-19 as well as with Barkley et al. (2020) who reported a $13.9 \%$ increase in sedentary behavior among university students after in-person classes were cancelled. In our study, many participants remarked that sitting had displaced PA typically accumulated throughout the day, especially for work-related tasks. They commented on increased screen time related to work and that there was no longer a need to move to attend meetings, talk to colleagues, etc. 


\section{Study Considerations}

Our study recruited a large sample geographically dispersed across 42 out of 50 states with the majority residing in the Midwest or South. Similarities between our sample and those from previous COVID-19 and PA survey research included the majority of respondents being female, white, married, and having higher incomes (Barkley et al., 2020; Dunton et al., 2020; Karuc et al., 2020; Lesser \& Nienhuis, 2020; Schuch et al., 2020). Two-thirds of our sample reporting working from home (66.3\%) compared to national reports of $35.2 \%$ (Bick et al., 2020). Our sample was highly active and seemed motivated to find ways to continue to participate in PA. There are also some limitations to our study that should be mentioned. Although PA questions were guided by the active living framework, self-report items are subject to recall and social desirability bias. Further, we did not objectively collect PA data and results should be interpreted as perceived change in PA. The cross-sectional nature of the survey should only be used to indicate associations and not causation. Finally, we note there are many variables that influence PA. Although we focused on gender, caregiving, and work location in current analyses, future work should further explore and/or control for additional variables of interest such as age, race, income, or education.

\section{Implications}

Findings from this study highlighted the domains and behavior settings that saw the greatest changes in PA. Creation of interventions and policies to improve PA during the pandemic should focus on accessible settings such as parks and trails, homes, or neighborhood environments, while taking into account the role that work location and caregiving responsibilities play in where and how people are active. Special attention should be made for those working at jobsites (i.e., essential or frontline workers) that also have caregiving responsibilities who are currently experiencing a decline in PA. Additionally, efforts should be made to reduce sedentary time, particularly for those with increased screen time, such as those working from home.

\section{Conclusion}

The overall increase in PA as well as ability of respondents to adapt to new PA domains and settings during a global pandemic was encouraging. As telework and childcare roles extend through the pandemic and beyond, future interventions should further identify and capitalize on domain- and setting-specific changes to promote innovative strategies for staying active.

\section{Correspondence should be addressed to}

Gina M. Besenyi

920 Denison Avenue

Manhattan, KS 66506

gbesenyi@ksu.edu

$\underline{785-532-0836}$

Gina M. Besenyi: 0000-0002-4538-9510

Emily L. Mailey: 0000-0001-7672-445X

Jeanette Gustat: 0000-0001-5597-1611

D. Katie M. Heinrich: 0000-0002-6837-408X

\section{Author Contributions}

Conceptualization, G.M.B, K.M.H., E.L.M., and J.G.; Methodology, G.M.B, K.M.H., E.L.M., J.G., O.P., J.D., and C.B.; Investigation, G.M.B, K.M.H., E.L.M., J.G., J.D., and C.B.; Writing - Original Draft, G.M.B, K.M.H., E.L.M., and O.P.; Writing - Review \& Editing, G.M.B, K.M.H., E.L.M., J.G., O.P., J.D., and C.B.; Project Administration, G.M.B.

Creative Commons License:

This work is licensed under a Creative Commons Attribution-Noncommercial 4.0 International License (CC BY-NC 4.0). 
Journal of Healthy Eating and Active Living

2021, Vol. 1, No. 4, pgs. 169-185

Table 1. Sample Demographics

\begin{tabular}{|c|c|c|}
\hline & $\mathrm{n}$ & $\%$ \\
\hline Total Sample & 805 & 100.0 \\
\hline \multicolumn{3}{|l|}{ Gender } \\
\hline Male & 163 & 20.2 \\
\hline Female & 628 & 78.0 \\
\hline \multicolumn{3}{|l|}{ Race } \\
\hline White & 682 & 84.7 \\
\hline Nonwhite & 115 & 14.3 \\
\hline Spanish, Hispanic, or Latino (Yes) & 54 & 6.7 \\
\hline \multicolumn{3}{|l|}{ Marital Status } \\
\hline Married/Unmarried Couple & 519 & 64.5 \\
\hline Divorced/Separated & 49 & 6.1 \\
\hline Widowed & 8 & 1.0 \\
\hline Never Married & 222 & 27.6 \\
\hline \multicolumn{3}{|l|}{ Employment Status } \\
\hline Working & 630 & 78.2 \\
\hline Not Working & 167 & 20.8 \\
\hline \multicolumn{3}{|l|}{ Education } \\
\hline High School & 23 & 2.9 \\
\hline Some College & 88 & 10.9 \\
\hline Associates Degree & 32 & 4.0 \\
\hline Bachelor's Degree & 232 & 28.8 \\
\hline Graduate Degree & 426 & 53.0 \\
\hline \multicolumn{3}{|l|}{ Income } \\
\hline$<\$ 20,000$ & 65 & 8.1 \\
\hline$\$ 20,000-\$ 60,000$ & 165 & 20.5 \\
\hline$\$ 60,001-\$ 100,000$ & 206 & 25.6 \\
\hline$+\$ 100,000$ & 283 & 35.2 \\
\hline \multicolumn{3}{|l|}{ Housing Type } \\
\hline Detached single family house & 542 & 67.3 \\
\hline Multi-family housing (apt, townhouse) & 248 & 30.7 \\
\hline Other & 12 & 1.5 \\
\hline \multicolumn{3}{|l|}{ Daily Life } \\
\hline Working from home & 534 & 66.3 \\
\hline Working at jobsite & 130 & 16.1 \\
\hline Caregiving (yes) & 254 & 31.6 \\
\hline Caregiving (no) & 551 & 68.4 \\
\hline \multicolumn{3}{|l|}{ Location } \\
\hline Northeast & 21 & 2.6 \\
\hline Midwest & 533 & 67.0 \\
\hline South & 169 & 21.2 \\
\hline West & 60 & 7.5 \\
\hline
\end{tabular}

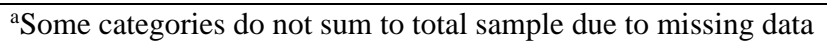




\section{Table 2. Physical Activity Domain and Participation During COVID-19 compared to Pre-Pandemic as a Function of Gender and Daily Living}

\begin{tabular}{|c|c|c|c|c|c|}
\hline \multicolumn{6}{|c|}{$\mathrm{n}(\%)$} \\
\hline & Lower & Same & Higher & $\chi^{2}$ & $\mathrm{P}$ value \\
\hline Recreational Physical Activity (n=804) & $288(35.8)$ & $154(19.1)$ & $362(44.9)$ & \multirow{3}{*}{16.61} & \multirow{3}{*}{$<0.001$} \\
\hline Male $(n=163)$ & $53(32.5)$ & $50(30.7)$ & $60(36.8)$ & & \\
\hline Female $(n=627)$ & $231(36.8)$ & $104(16.6)$ & $292(46.6)$ & & \\
\hline Working from home $(n=534)$ & $186(34.8)$ & $88(16.5)$ & $260(46.8)$ & \multirow[t]{2}{*}{9.80} & \multirow[t]{2}{*}{0.007} \\
\hline Working at jobsite $(n=129)$ & $47(36.4)$ & $35(27.1)$ & $47(36.4)$ & & \\
\hline Occupational Physical Activity $(\mathrm{n}=697)$ & $411(51.1)$ & $229(28.4)$ & $57(7.0)$ & \multirow{3}{*}{41.83} & \multirow{3}{*}{$<0.001$} \\
\hline Working from home $(\mathrm{n}=475)$ & $296(62.3)$ & $155(32.6)$ & $24(5.1)$ & & \\
\hline Working at jobsite $(n=126)$ & $46(36.5)$ & $55(43.7)$ & $25(19.8)$ & & \\
\hline Active Transportation $(\mathrm{n}=752)$ & $379(47.1)$ & $234(29.1)$ & $139(17.2)$ & \multirow{3}{*}{26.08} & \multirow{3}{*}{$<0.001$} \\
\hline Working from home $(\mathrm{n}=500)$ & $275(55.0)$ & $134(26.8)$ & $91(18.2)$ & & \\
\hline Working at jobsite $(n=120)$ & $37(30.8)$ & $58(48.3)$ & $25(20.8)$ & & \\
\hline Household Physical Activity $(\mathrm{n}=805)$ & $67(8.4)$ & $288(35.8)$ & $450(55.9)$ & \multirow{3}{*}{9.82} & \multirow{3}{*}{0.007} \\
\hline Caregiving $(n=254)$ & $15(5.9)$ & $77(30.3)$ & $162(63.8)$ & & \\
\hline No caregiving $(n=551)$ & $52(9.4)$ & $211(38.3)$ & $288(52.3)$ & & \\
\hline Use of Public Transportation $(n=372)$ & $207(25.7)$ & $164(20.4)$ & $1(0.1)$ & \multirow{3}{*}{10.71} & \multirow{3}{*}{0.005} \\
\hline Working from home $(n=253)$ & $147(58.1)$ & $105(41.5)$ & $1(0.04)$ & & \\
\hline Working at jobsite $(\mathrm{n}=53)$ & $18(35.8)$ & $35(66.0)$ & $0(0)$ & & \\
\hline Duration of Physical Activity $(\mathrm{n}=801)$ & $269(33.4)$ & $160(19.9)$ & $372(46.2)$ & \multirow{3}{*}{20.38} & \multirow{3}{*}{$<0.001$} \\
\hline Male $(n=163)$ & $45(27.6)$ & $53(32.5)$ & $65(40.0)$ & & \\
\hline Female $(n=624)$ & $219(35.1)$ & $104(16.7)$ & $301(48.2)$ & & \\
\hline Frequency of Physical Activity $(\mathrm{n}=801)$ & $208(25.8)$ & $239(29.7)$ & $354(43.9)$ & \multirow{3}{*}{10.52} & \multirow{3}{*}{0.005} \\
\hline Male $(n=163)$ & $36(22.1)$ & $66(40.5)$ & $61(37.4)$ & & \\
\hline Female $(n=624)$ & $169(27.1)$ & $171(27.4)$ & $284(45.5)$ & & \\
\hline Caregiving $(\mathrm{n}=252)$ & $58(23.0)$ & $64(25.4)$ & $130(51.6)$ & \multirow[t]{2}{*}{8.21} & \multirow[t]{2}{*}{0.02} \\
\hline No caregiving $(n=549)$ & $150(27.3)$ & $175(31.9)$ & $224(40.8)$ & & \\
\hline Time Sitting $(\mathrm{n}=803)$ & $121(15.1)$ & $193(24.0)$ & $489(60.7)$ & \multirow{3}{*}{20.55} & \multirow{3}{*}{$<0.001$} \\
\hline Caregiving $(n=254)$ & $58(22.8)$ & $65(25.6)$ & $131(51.6)$ & & \\
\hline No caregiving $(n=549)$ & $63(11.5)$ & $128(23.3)$ & $358(65.2)$ & & \\
\hline & Disagree & Neither & Agree & \multirow{4}{*}{5.97} & \multirow{4}{*}{0.05} \\
\hline Mode Changed $(n=805)$ & $95(11.8)$ & $92(11.4)$ & $618(76.8)$ & & \\
\hline Male $(n=163)$ & $21(12.9)$ & $27(16.6)$ & $115(70.6)$ & & \\
\hline Female $(n=628)$ & $74(11.8)$ & $63(10.0)$ & $491(78.2)$ & & \\
\hline Location Changed $(n=805)$ & $89(11.1)$ & $80(9.9)$ & $636(79.0)$ & \multirow{4}{*}{13.44} & \multirow{4}{*}{0.001} \\
\hline Reason Changed $(\mathrm{n}=805)$ & $185(23.0)$ & $189(23.5)$ & $431(53.5)$ & & \\
\hline Caregiving $(\mathrm{n}=254)$ & $45(17.7)$ & $49(19.3)$ & $160(63.0)$ & & \\
\hline No caregiving $(\mathrm{n}=551)$ & $140(25.4)$ & $140(25.4)$ & $271(49.2)$ & & \\
\hline
\end{tabular}

${ }^{\mathrm{a} O n l y}$ statistically significant results $(p<.05)$ from chi-squared analyses are included in table 
Journal of Healthy Eating and Active Living

2021, Vol. 1, No. 4, pgs. 169-185

Table 3. Physical Activity Across Settings Before and During COVID-19

\begin{tabular}{|c|c|c|c|c|c|}
\hline & $\begin{array}{l}\text { No PA (0 } \\
\text { Min) }\end{array}$ & $\begin{array}{c}\text { Low } \\
\text { Insufficient (1- } \\
59 \text { Min) } \\
\end{array}$ & $\begin{array}{c}\text { Moderate } \\
\text { Insufficient (60- } \\
149 \mathrm{Min}) \\
\end{array}$ & $\begin{array}{c}\text { Sufficient } \\
(150-299 \\
\text { Min) } \\
\end{array}$ & $\begin{array}{c}\text { Exceeds }(>300 \\
\text { Min) }\end{array}$ \\
\hline & $\mathrm{n}(\%)$ & $\mathrm{n}(\%)$ & $\mathrm{n}(\%)$ & $\mathrm{n}(\%)$ & $\mathrm{n}(\%)$ \\
\hline \multicolumn{6}{|c|}{ Parks/Trails } \\
\hline Before & $246(30.6)$ & $250(31.1)$ & $211(26.2)$ & $48(6.0)$ & $31(3.9)$ \\
\hline During & $290(36.0)$ & $168(20.9)$ & $199(24.7)$ & $80(9.9)$ & $61(7.6)$ \\
\hline \multicolumn{6}{|c|}{ Recreational Sports } \\
\hline Before & $583(72.4)$ & $86(10.7)$ & $90(11.2)$ & $28(3.5)$ & $14(1.7)$ \\
\hline During & 748 (92.9) & $25(3.1)$ & $15(1.9)$ & $4(0.5)$ & $8(1.0)$ \\
\hline \multicolumn{6}{|c|}{ Neighborhoods } \\
\hline Before & $114(14.2)$ & $245(35.2)$ & $283(35.2)$ & $95(11.8)$ & $52(6.5)$ \\
\hline During & $82(10.2)$ & $160(19.9)$ & $283(35.2)$ & $176(21.9)$ & $101(12.5)$ \\
\hline \multicolumn{6}{|l|}{ Home } \\
\hline Before & $135(16.8)$ & $214(26.6)$ & $298(37.0)$ & $88(10.9)$ & $67(8.3)$ \\
\hline During & $33(4.1)$ & $92(11.4)$ & $277(34.4)$ & $220(27.3)$ & $178(22.1)$ \\
\hline \multicolumn{6}{|c|}{ Fitness Facilities } \\
\hline Before & $307(38.1)$ & $68(8.4)$ & $157(19.5)$ & $147(18.3)$ & $123(15.3)$ \\
\hline During & $787(97.8)$ & $4(0.5)$ & $6(0.7)$ & $3(0.4)$ & $2(0.2)$ \\
\hline \multicolumn{6}{|l|}{ Total } \\
\hline Before & $14(1.7)$ & $45(5.6)$ & $93(11.6)$ & $209(26.0)$ & $443(55.0)$ \\
\hline During & $6(0.7)$ & $40(5.0)$ & $90(11.2)$ & $171(21.2)$ & $497(61.7)$ \\
\hline
\end{tabular}


Journal of Healthy Eating and Active Living

2021, Vol. 1, No. 4, pgs. 169-185

Table 4. Physical Activity Across Settings Before and During COVID and Interactions with Work Location, Caregiving, and Gender

\begin{tabular}{lcccc}
\hline Source & $\mathrm{F}$ & $\mathrm{df}$ & $\mathrm{sig}$ & $\eta_{\mathrm{p}}^{2}$ \\
\hline Parks/Trails PA & 1.78 & 1 & .183 & .003 \\
Recreational Sports PA & $\mathbf{6 6 . 0 0}$ & $\mathbf{1}$ & $\mathbf{. 0 0 0}$ & $\mathbf{. 0 9 3}$ \\
$\quad$ Recreational Sports * Gender & $\mathbf{1 0 . 8 0}$ & $\mathbf{1}$ & $\mathbf{. 0 0 1}$ & $\mathbf{. 0 1 7}$ \\
Neighborhood PA & $\mathbf{2 6 . 4 4}$ & $\mathbf{1}$ & $\mathbf{. 0 0 0}$ & $\mathbf{. 0 4 0}$ \\
$\quad$ Neighborhood PA * Work Location & $\mathbf{4 . 9 3}$ & $\mathbf{1}$ & $\mathbf{. 0 2 7}$ & $\mathbf{. 0 0 8}$ \\
Home-based PA & $\mathbf{1 2 0 . 3 1}$ & $\mathbf{1}$ & $\mathbf{. 0 0 0}$ & $\mathbf{. 1 5 8}$ \\
Home-based PA * Caregiving & $\mathbf{6 . 3 1}$ & $\mathbf{1}$ & $\mathbf{. 0 1 2}$ & $\mathbf{. 0 1 0}$ \\
Total PA & 0.26 & 1 & .608 & .000 \\
Total PA * Work Location & $\mathbf{9 . 8 5}$ & $\mathbf{1}$ & $\mathbf{. 0 0 2}$ & $\mathbf{. 0 1 5}$ \\
Total PA * Work Location * Caregiving & $\mathbf{4 . 2 3}$ & $\mathbf{1}$ & $\mathbf{. 0 4 0}$ & $\mathbf{. 0 0 6}$
\end{tabular}




\begin{tabular}{|c|c|}
\hline Effect on PA & Exemplar quotes \\
\hline $\begin{array}{l}\text { Decrease in } \\
\text { occupational } \\
\text { activity }\end{array}$ & $\begin{array}{l}\text { - I use to walk a lot more in the office and take the stairs multiple times per day. I also used to stand at } \\
\text { my desk } \\
\text { As a teacher I am on my feet walking around the classroom and hallways all day long. Being online } \\
\text { forces me to sit in front of a screen way too many hours of the day. } \\
\text { - I have a desk job and have lost the casual movement around the office and walking from meeting to } \\
\text { meeting. Now all my meetings are at one desk. I am making effort to pace during calls and take a } \\
\text { walk around the block when I can. }\end{array}$ \\
\hline $\begin{array}{l}\text { Decrease in active } \\
\text { transportation }\end{array}$ & $\begin{array}{l}\text { - Rather than walking on campus to get from meeting to meeting, I've had to focus on taking time } \\
\text { every day to ensure I get similar amounts of physical activity } \\
\text { - I used to walk to and from campus nearly every day, now I barely leave my apartment. } \\
\text { Instead of walking my child to school and back twice a day or scootering I need to take him out to } \\
\text { scooter so he gets exercise and this cuts out about } 40 \text { minutes of walking or scootering Monday } \\
\text { through Friday. Which was unavoidable exercise and now it's so far much less because I'm busy or } \\
\text { tired }\end{array}$ \\
\hline $\begin{array}{l}\text { Increased sitting } \\
\text { time }\end{array}$ & $\begin{array}{l}\text { - I'm working remotely on COVID-19 response. In the past I would do this by physically responding } \\
\text { to response but am spending } 16+\text { hours a day at a computer usually in virtual coordination meetings. } \\
\text { I would like to go outside to exercise but I don't have time. } \\
\text { - My gym is closed so I no longer go to fitness classes and I work } 100 \% \text { at home remotely now so I sit } \\
\text { all day at my desk. } \\
\text { I need to get out for a walk to keep me sane as I am stuck at a computer for way too long each day } \\
\text { now that I work from home. }\end{array}$ \\
\hline $\begin{array}{l}\text { No PA at fitness } \\
\text { facilities }\end{array}$ & $\begin{array}{l}\text { - I used to go to the athletic club @ 5am nearly every work day (M-F) to run on the indoor track or } \\
\text { treadmill, lift weights, or swim. I cannot do any of that now. Now I'm doing yoga/stretching in my } \\
\text { apartment most mornings and short runs outside 2-3 times/week. } \\
\text { I can no longer go to the gym and with } 2 \text { little kids at home it makes it nearly impossible to get a } \\
\text { workout in. Instead we take walks and go on family disc golf outings. } \\
\text { I typically workout at the gym, and now that the gyms are closed, I have to work out in my own } \\
\text { home, which is not as motivating for me. }\end{array}$ \\
\hline $\begin{array}{l}\text { Increase in } \\
\text { outdoor PA }\end{array}$ & $\begin{array}{l}\text { - Our family is using the weekends to travel to different hiking areas and historical areas in [our state]. } \\
\text { The reason is that we are bored of home, we have less work to complete over the weekends, and we } \\
\text { can still socially distance. This is a more active routine that usual. } \\
\text { - Since working remotely, I have begun almost daily morning hikes. When working in an office I was } \\
\text { unable to participate in morning physical activities due to time constraints. Because if this my } \\
\text { physical activity has increased } \\
\text { Lots of playing with my } 4 \text { year old son, gardening, playing in the water, biking and walking that I } \\
\text { wasn't able to do while working. }\end{array}$ \\
\hline
\end{tabular}


Journal of Healthy Eating and Active Living

2021, Vol. 1, No. 4, pgs. 169-185

\begin{tabular}{|l|l|l|}
\hline Increased home- & $\bullet$ & $\begin{array}{l}\text { I am home more so I am naturally more active because of the small children and the 'spring' } \\
\text { cleaning/organizing that I'm getting into. My Fitbit says I am doing more, but that it's not official } \\
\text { PA, just doing stuff around the house and yard and with the kids. Way more active, way less } \\
\text { sedentary. }\end{array}$ \\
& $\begin{array}{l}\text { Less walking around for work than when I was physically going into my office but I'm spending } \\
\text { more time during the day doing things around the house such as cleaning and yardwork when I break } \\
\text { from work stuff. } \\
\text { Working from home allows me to have more time to work to do housework, work in yard, plant } \\
\text { garden, trim trees, etc. due to time gained in not commuting, no physical meetings and minimal trips } \\
\text { to store. }\end{array}$ \\
\hline New modes of PA & $\begin{array}{l}\text { I went from doing weight training to purely cardio/HIIT training since being at home. } \\
\text { I have started trying different exercises, especially ones that do not require equipment or space. For } \\
\text { example, instead of lifting weights, I have been doing yoga. } \\
\text { No longer able to access a gym; so have been doing more hiking/walking/jogging and utilizing free } \\
\text { weights at home }\end{array}$ \\
&
\end{tabular}




\section{References}

Amatriain-Fernández, S., Murillo-Rodríguez, E. S., Gronwald, T., Machado, S., \& Budde, H. (2020). Benefits of physical activity and physical exercise in the time of pandemic. Psychological Trauma: Theory, Research, Practice, and Policy, 12(S1), S264.

Ammar, A., Trabelsi, K., Brach, M., Chtourou, H., Boukhris, O., Masmoudi, L., Bouaziz, B., Bentlage, E., How, D., \& Ahmed, M. (2020). Effects of home confinement on mental health and lifestyle behaviours during the COVID-19 outbreak: Insight from the" ECLB-COVID19" multi countries survey. medRxiv.

Barkley, J. E., Lepp, A., Glickman, E., Farnell, G., Beiting, J., Wiet, R., \& Dowdell, B. (2020). The Acute Effects of the COVID19 Pandemic on Physical Activity and Sedentary Behavior in University Students and Employees. International Journal of Exercise Science, 13(5), 1326.

Basso, J. C. \& Suzuki, W. A. (2017). The effects of acute exercise on mood, cognition, neurophysiology, and neurochemical pathways: a review. Brain Plasticity, 2(2), 127-152.

Bick, A., Blandin, A., \& Mertens, K. (2020). Work from home after the COVID-19 Outbreak.

Callow, D. D., Arnold-Nedimala, N. A., Jordan, L. S., Pena, G. S., Won, J., Woodard, J. L., \& Smith, J. C. (2020). The Mental Health Benefits of Physical Activity in Older Adults Survive the COVID-19 Pandemic. The American Journal of Geriatric Psychiatry, 28(10), 1046-1057. https://doi.org/https://doi.org/10.1016/j.jagp.2020.06.024

Campbell, J. P. \& Turner, J. E. (2018). Debunking the myth of exercise-induced immune suppression: redefining the impact of exercise on immunological health across the lifespan. Frontiers in Immunology, 9, 648.

Carlson, D. L., Petts, R., \& Pepin, J. (2020). US Couples' Divisions of Housework and Childcare During COVID-19 Pandemic.

Center for Disease Control and Prevention (CDC). (2019). Frequently Asked Questions. Retrieved Oct. 21, 2019 from https://www.cdc.gov/coronavirus/2019-ncov/faq.html

Center for Disease Control and Prevention (CDC). (2020). How to Protect Yourself \& Others. Retrieved October 21 from https://www.cdc.gov/coronavirus/2019-ncov/prevent-getting-sick/prevention.html

Charmaz, K. (2006). Constructing grounded theory: A practical guide through qualitative analysis. Sage Publications. Retrieved October 12 from http://www.sxf.uevora.pt/wp-content/uploads/2013/03/Charmaz_2006.pdf

Chen, P., Mao, L., Nassis, G. P., Harmer, P., Ainsworth, B. E., \& Li, F. (2020). Coronavirus disease (COVID-19): The need to maintain regular physical activity while taking precautions. Journal of Sport and Health Science, 9(2), 103-104. https://doi.org/https://doi.org/10.1016/i.jshs.2020.02.001

Cucinotta, D. \& Vanelli, M. (2020). WHO Declares COVID-19 a Pandemic. Acta Bio-Medica: Atenei Parmensis, 91(1), $157-$ 160. https://doi.org/10.23750/abm.v91i1.9397 
Del Boca, D., Oggero, N., Profeta, P., \& Rossi, M. (2020). Women's and men's work, housework and childcare, before and during COVID-19. Review of Economics of the Household, 18(4), 1001-1017.

Dunton, G. F., Wang, S. D., Do, B., \& Courtney, J. (2020). Early effects of the COVID-19 pandemic on physical activity locations and behaviors in adults living in the United States. Preventive medicine reports, 20, 101241. https://doi.org/https://doi.org/10.1016/j.pmedr.2020.101241

Galper, D. I., Trivedi, M. H., Barlow, C. E., Dunn, A. L., \& Kampert, J. B. (2006). Inverse association between physical inactivity and mental health in men and women. Medicine and Science in Sports and Exercise, 38(1), 173-178.

Jones, A. W. \& Davison, G. (2019). Exercise, Immunity, and Illness. In Muscle and Exercise Physiology (pp. 317-344). Elsevier.

Jurak, G., Morrison, S. A., Leskošek, B., Kovač, M., Hadžić, V., Vodičar, J., Truden, P., \& Starc, G. (2020). Physical activity recommendations during the COVID-19 virus outbreak. Journal of Sport and Health Science.

Karuc, J., Sorić, M., Radman, I., \& Mišigoj-Duraković, M. (2020). Moderators of Change in Physical Activity Levels during Restrictions Due to COVID-19 Pandemic in Young Urban Adults. Sustainability, 12(16), 6392.

Knell, G., Robertson, M. C., Dooley, E. E., Burford, K., \& Mendez, K. S. (2020). Health Behavior Changes During COVID-19 Pandemic and Subsequent "Stay-at-Home” Orders. International Journal of Environmental Research and Public Health, 17(17), 6268. https://www.mdpi.com/1660-4601/17/17/6268

Lee, D. H., de Rezende, L. F. M., Eluf-Neto, J., Wu, K., Tabung, F. K., \& Giovannucci, E. L. (2019). Association of type and intensity of physical activity with plasma biomarkers of inflammation and insulin response. International Journal of Cancer, 145(2), 360-369.

Lesser, I. A. \& Nienhuis, C. P. (2020). The Impact of COVID-19 on Physical Activity Behavior and Well-Being of Canadians. International Journal of Environmental Research and Public Health, 17(11), 3899.

López-Bueno, R., Calatayud, J., Ezzatvar, Y., Casajús, J. A., Smith, L., Andersen, L. L., \& Lopez-Sanchez, G. F. (2020). Association between current physical activity and current perceived anxiety and mood in the initial phase of COVID-19 confinement. Frontiers in psychiatry, 11 .

Maugeri, G., Castrogiovanni, P., Battaglia, G., Pippi, R., D'Agata, V., Palma, A., Di Rosa, M., \& Musumeci, G. (2020). The impact of physical activity on psychological health during Covid-19 pandemic in Italy. Heliyon, 6(6), e04315. https://doi.org/https://doi.org/10.1016/j.heliyon.2020.e04315

Moreland, A., Herlihy, C., Tynan, M. A., Sunshine, G., McCord, R. F., Hilton, C., Poovey, J., Werner, A. K., Jones, C. D., \& Fulmer, E. B. (2020). Timing of state and territorial COVID-19 stay-at-home orders and changes in population movement-United States, March 1-May 31, 2020. Morbidity and Mortality Weekly Report, 69(35), 1198.

Nieman, D. C. \& Wentz, L. M. (2019). The compelling link between physical activity and the body's defense system. Journal of Sport and Health Science, 8(3), 201-217. 
Powell, K. E., King, A. C., Buchner, D. M., Campbell, W. W., DiPietro, L., Erickson, K. I., Hillman, C. H., Jakicic, J. M., Janz, K. F., \& Katzmarzyk, P. T. (2019). The Scientific Foundation for the Physical Activity Guidelines for Americans, 2nd Edition. Journal of Physical Activity and Health, 16, 1-11.

Prados, M. \& Zamarro, G. (2020). Gender Differences in Couples’ Division of Childcare, Work and Mental Health During COVID-19. CESR-Schaeffer Working Paper(003).

Qi, M., Li, P., Moyle, W., Weeks, B., \& Jones, C. (2020). Physical activity, health-related quality of life, and stress among the Chinese adult population during the COVID-19 pandemic. International Journal of Environmental Research and Public Health, 17(18), 6494.

Sallis, J. F., Cervero, R. B., Ascher, W., Henderson, K. A., Kraft, M. K., \& Kerr, J. (2006). An ecological approach to creating active living communities. Annual Review of Public Health, 27(Journal Article), 297-322. https://doi.org/10.1146/annurev.publhealth.27.021405.102100

Schuch, F. B., Bulzing, R. A., Meyer, J., Vancampfort, D., Firth, J., Stubbs, B., Grabovac, I., Willeit, P., Tavares, V. D. O., Calegaro, V. C., Deenik, J., López-Sánchez, G. F., Veronese, N., Caperchione, C. M., Sadarangani, K. P., Abufaraj, M., Tully, M. A., \& Smith, L. (2020). Associations of moderate to vigorous physical activity and sedentary behavior with depressive and anxiety symptoms in self-isolating people during the COVID-19 pandemic: A cross-sectional survey in Brazil. Psychiatry Research, 292, 113339. https://doi.org/https://doi.org/10.1016/j.psychres.2020.113339

Shamshiripour, A., Rahimi, E., Shabanpour, R., \& Mohammadian, A. K. (2020). How is COVID-19 reshaping activity-travel behavior? Evidence from a comprehensive survey in Chicago. Transportation Research Interdisciplinary Perspectives, $7,100216$.

U.S. Chamber of Commerce Foundation Center for Education and Workforce. (2020). Piecing Together Solutions: The Importance of Childcare to U.S. Families and Businesses. https://www.uschamberfoundation.org/sites/default/files/EarlyEd_Minis_Report6_121420_Final.pdf

Woods, J., Hutchinson, N. T., Powers, S. K., Roberts, W. O., Gomez-Cabrera, M. C., Radak, Z., Berkes, I., Boros, A., Boldogh, I., \& Leeuwenburgh, C. (2020). The COVID-19 pandemic and physical activity. In: Elsevier.

World Health Organization. (2020). Coronavirus disease 2019 Q\&A. Retrieved October 22 from https://www.who.int/emergencies/diseases/novel-coronavirus-2019 
Journal of Healthy Eating and Active Living

2021, Vol. 1, No. 4, pgs. 169-185

Appendix

Figure 1a

Self-reported Changes in Physical Activity Participation Across Domains

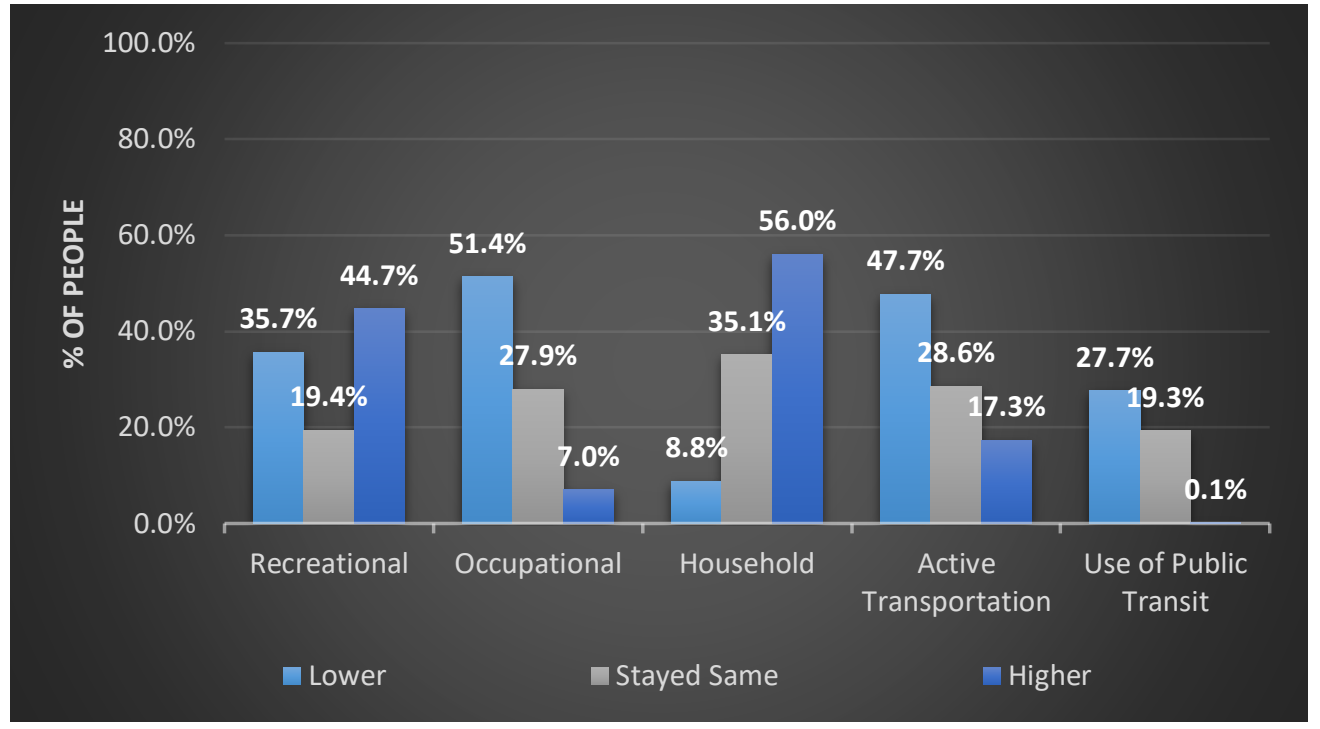

Note. These changes are across all demographics and domains.

\section{Figure 1b}

Self-reported Changes in Physical Activity Duration, Frequency, and Sitting

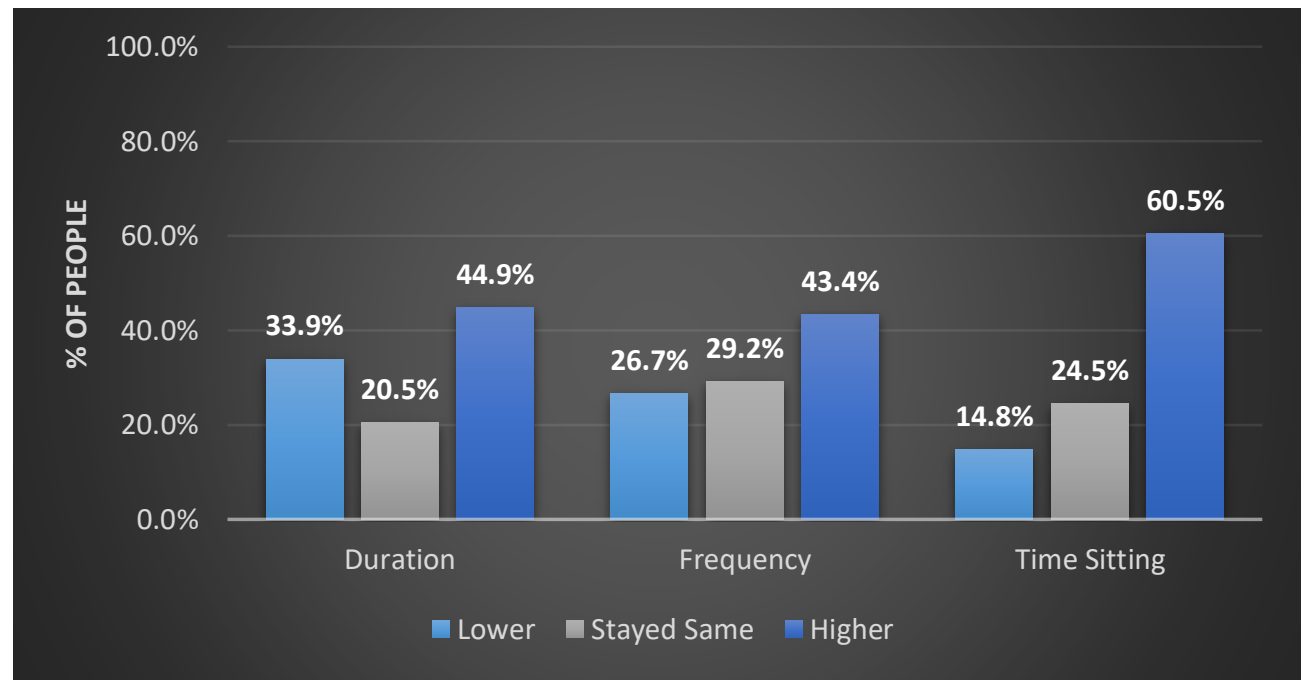

Note. These changes are across all demographics and domains. 
Journal of Healthy Eating and Active Living

2021, Vol. 1, No. 4, pgs. 169-185

\section{Figure 1c}

Self-reported Changes in Physical Activity Participation Mode Location and Reason

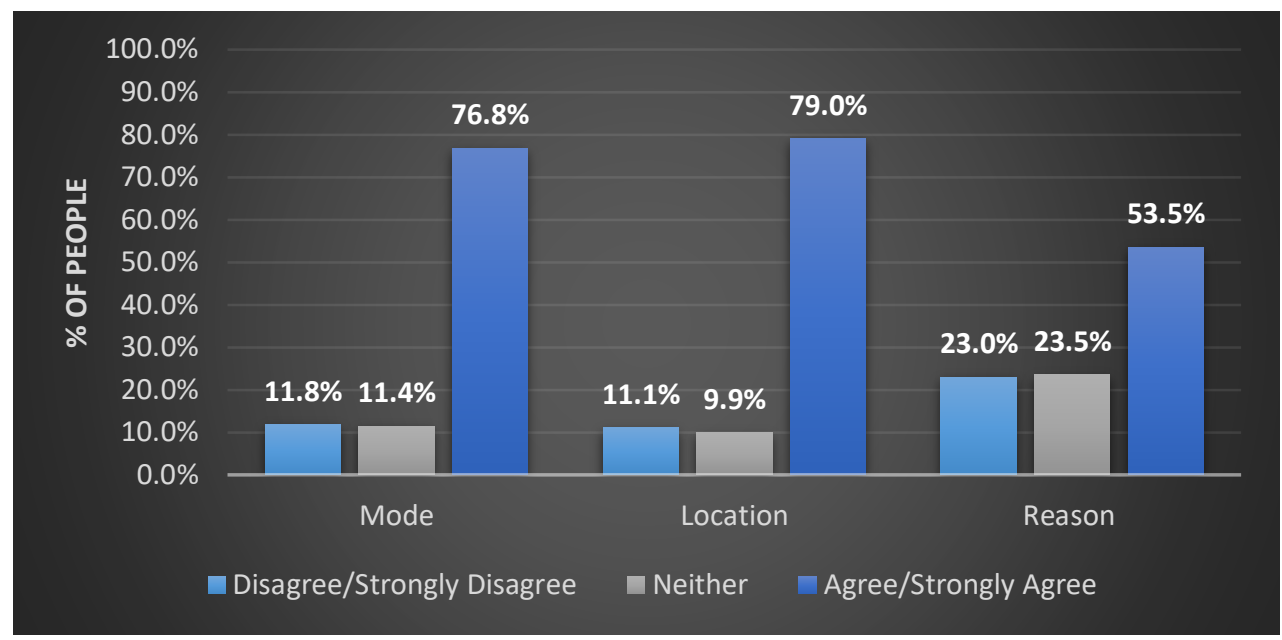

Note. These changes are across all demographics and domains.

\section{Figure 2}

Self-reported Changes in Weekly Minutes of Physical Activity Across Settings Before and During COVID-19

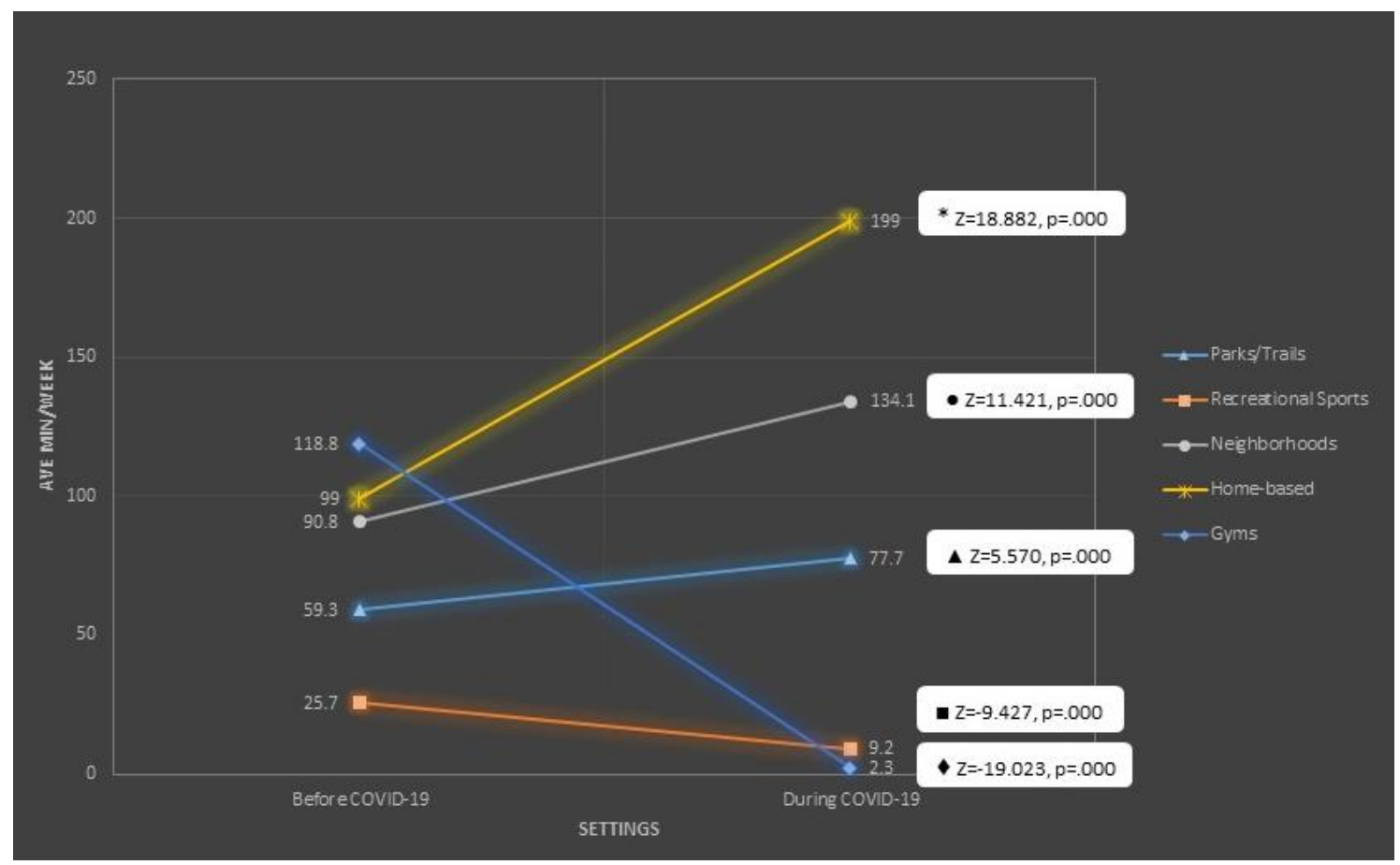

Note. These changes are across all demographics and domains. 